\title{
Measurement of cumulative radiation exposure to children and adolescents in contact with outpatients treated with low dose radioactive iodine $\left({ }^{131} \mathrm{I}\right)$
}

Khaled Salman ${ }^{1}$, Shereen Wagieh ${ }^{2^{*}}$, Aquib Bakhsh${ }^{1}$, Tarek Al-Monshy ${ }^{1}$, Omnia Talaat ${ }^{3}$, Musaed Al-Malki ${ }^{4}$, Manal Al-Ezzi ${ }^{1}$, Ashraf Fouda ${ }^{2}$ and Gihad Hamid ${ }^{2}$

\begin{abstract}
Background: Radiation exposure from patients treated with radioactive iodine $\left({ }^{131} I\right)$ represents a radiation hazard to children and adolescents, representing the most vulnerable group of household contacts. Our aim was to calculate the cumulative radiation exposure (CRE) figures to children and adolescents sharing the same home with outpatients treated with low-dose ${ }^{131} \mathrm{I}$. The secondary aim was to study the demographic and educational factors that may significantly affect radiation exposure to them.

Results: The whole number of household contacts less than 18 years was 99 , out of them $49 \leq 12$ years. CRE level to children and adolescents ranged from 79 to 934 USv. The mean, median, and 75th percentile figures were $284 \pm$ 178 uSv, 215 uSv, and 334 uSv, respectively. The compliance of this group of contacts to radiation exposure constraint (1 mSv) was 100\%. All CRE values were below this figure with $75 \%$ of them below half of this constraint. Thirteen adolescents from 12 to 18 years and 17 mothers of 23 household contacts $\leq 12$ years got radiation safety instructions (RSI) directly from a radiation safety officer (RSO). This group had a significantly lower mean CRE value (184 \pm 93 uSv) compared to those who got RSI from the patient or from other family members (298 \pm 185 uSv) with a significant $p$ value.

Conclusion: The compliance of adolescents and children to the 1-mSv radiation exposure constraint is 100\%. It is advised for adolescents and mothers of children in contact with ${ }^{131} \mathrm{I}$-treated patients to get direct RSI from the RSO, which is the only factor associated with significantly lower radiation exposure figures.
\end{abstract}

Keywords: Radiation exposure, Children and adolescents, Outpatients treatment, Low-dose radioactive iodine $\left({ }^{131} \mathrm{I}\right)$

\section{Background}

Radioactive iodine $\left({ }^{131} \mathrm{I}\right)$ therapy is a widely employed therapeutic modality for patients with Graves' disease, toxic nodular disease, and well-differentiated thyroid cancer either for postoperative ablation or for treatment of metastatic disease. It has been proven to be a safe and relatively inexpensive therapy. Therapeutic doses of ${ }^{131} \mathrm{I}$ commonly range from 100 to $7400 \mathrm{MBq}$. The lower activity is used for the treatment of toxic goiter, and higher

\footnotetext{
* Correspondence: dr.sherinyassin@gmail.com

${ }^{2}$ King Abdullah Medical City (KAMC), Jeddah Oncology Centre, Jeddah, Saudi Arabia

Full list of author information is available at the end of the article
}

doses are employed to treat metastatic disease in patients with well-differentiated thyroid cancer. The use of higher doses usually requires hospitalization in a special isolation room for few days, and $30 \mathrm{mCi}(1110 \mathrm{MBq})$ was reported as the highest low ${ }^{131}$ I dose approved for outpatient therapy in many countries. It is considered the maximum permissible radioactivity for ambulatory treatment. After ${ }^{131}$ I therapy, the patient becomes a potential radiation hazard to other individuals including household contacts $[1,2]$.

There is a common agreement of $1 \mathrm{mSv} /$ year dose constraint of radiation exposure from patients treated with ${ }^{131}$ I to children and adolescents between different 
associations concerned with radiation protection $[3,4]$. The smaller constraint for children and young adults is due to the fact that the risk of cancer incidence is the highest at a younger age after exposure to radiation [5, 6]. Ionizing radiation is a well-known carcinogen to which children are particularly more vulnerable due to greater cell division in growing and developing tissues with an expected longer lifetime, increasing the chance of repeated exposure and accumulated damage, with resultant higher cancer risk for children [7].

Awareness and concerns about radiation exposure to children and adolescents increased substantially after major radiation accidents. A lot of epidemiological studies have investigated the link between the Chernobyl accident and cancer and had largely focused on malignant diseases in children, specifically thyroid cancer [8-10]. Recently, Yamashita et al. [11] reported that radiation exposure post-nuclear accidents resulted in an increase in the risk of late-onset thyroid cancer, mainly due to the release of ${ }^{131} \mathrm{I}$ in the fallout; this risk was particularly elevated in those exposed during infancy, childhood, and adolescence. There are many ways to maximally reduce exposure of children and adolescents to ionizing radiation without sacrificing diagnostic reliability during CT scanning and hybrid imaging [12-15]. However, radiation hazards have made clinicians skeptical about the treatment usage of ${ }^{131} \mathrm{I}$ in children with Graves' disorders $[16,17]$ despite some reports confirming the safety of this therapeutic modality in young age $[18,19]$.

Many studies have been published to measure radiation exposure to household contacts of patients treated with ${ }^{131}$ I. They confirmed proper compliance with radiation exposure constraints. Yet, few studies about this issue have been conducted in the Middle East. To our knowledge, this is the first study in the Middle East concerned with the measurement of radiation exposure to children and adolescents sharing the same home with outpatients treated with low-dose ${ }^{131} \mathrm{I}$.

\section{Aim}

Our study aimed at measuring the external cumulative radiation exposure (CRE) in the post-therapy period to children and adolescents who shared the same home with patients treated with low-dose ${ }^{131}$ I on an outpatient basis in the post-therapy period and their compliance to radiation exposure constraint. The secondary aim was to search for any demographic or educational factor that may affect radiation exposure to this vulnerable group of contacts.

\section{Methods}

The current study was conducted after submission to and approval by the institutional ethics committee and IRB committee. Our study was a prospective study conducted from May 2015 to August 2018 on children and adolescents of well-oriented self-dependent adult patients referred for low-dose $(\leq 30 \mathrm{mCi})$ radioactive iodine therapy on an outpatient basis. The maximum low ${ }^{131}$ I dose that can be given on an outpatient basis in many centers including ours is $1110 \mathrm{MBq}(30 \mathrm{mCi})$, on giving higher activity hospitalization in a special isolation room becomes a must. Patients presented for low-dose ${ }^{131}$ I therapy $(<30 \mathrm{mCi})$ either for the treatment of toxic goiter or for postoperative ablation in patients with welldifferentiated thyroid cancer. The prescribed dose for those with toxic goiter ranged from 370 to $740 \mathrm{MBq}$ $(10-20 \mathrm{mCi})$, while for postoperative ablation in patients with well-differentiated thyroid cancer, the dose was $1110 \mathrm{MBq}(30 \mathrm{mCi})$.

The home requirements needed were the presence of a separate bedroom and bathroom to be used by the patient only for few days post-therapy. Also, no pregnant ladies should be in the household area at least 5 days post-therapy together with the willingness of both the patient and all contacts to precisely follow the given radiation safety instructions. The study included two visits.

\section{First visit}

Radiation safety instructions (RSI) were given in details to the patient by the radiation safety officer (RSO). Also, the aim of the study was explained to the patient including measuring external CRE to children and adolescents in the first 5 days post- ${ }^{131}$ I intake using thermoluminescent dosimeters (TLDs). The most important instruction for patients is to restrict contact time with household contacts, especially children and adolescents. The patient should use a separate bathroom and bedroom for a variable period of time, ranging from 1 to 2 weeks, depending on his/her clinical status whether toxic goiter or cancer thyroid and on the given ${ }^{131}$ I dose. If the patient is a nursing woman, she should stop breastfeeding posttherapy for her current lactation episode. Female patients in the childbearing period should have a negative pregnancy test prior to therapy, and they have to avoid pregnancy for 6 months to 1 year after receiving ${ }^{131} \mathrm{I}$ therapy. Also, patients should use separate dining tools that should be cleaned separately. Instructions for personal hygiene are also important with urination in the sitting position for men and toilets have to be flushed three times after use with proper hand wash after coming from the bathroom. Everything related to patients from linens, cloth, and towels have to be washed separately for 1 week. The RSO highlighted the importance of keeping enough distance between patients' aid companion and the patient during returning home, transportation, and during daily contact. The distance should be kept at least one to one and a half meters from the patient for a restricted period of time. The more the 
distance and the less the time of household contact with the patient, the more the reduction of radiation exposure. This is more important for children and adolescents especially in the first week post-therapy to reduce radiation exposure and to achieve the as low as reasonably achievable (ALARA) principle. Further instructions included taking time off from work, restrict the use of public transportation, and avoiding intercourse for variable periods of time, ranging from 1 to 2 weeks, according to different factors including the type of work, the dose given to the patient, and the underlying disease. By the end of this meeting, the participant and his/her family member/s confirmed their understanding of all given instructions and the ability to transfer them to the rest of the family members. For patients who agreed to participate in the study, a consent form was signed. The purpose of using the TLDs to measure CRE together with how and when to be applied was clearly understood. By the end of this visit, a hard copy of RSI was given to be discussed with family members. The patient was scheduled for a second visit for ${ }^{131}$ I therapy. Also, upon agreement to join the study, the patients were asked to be accompanied by one or more of their family members in the second visit for direct education about RSI, preferably adolescents or mothers of children below 12 years living with the patient in the same house.

\section{Second visit}

The patient presented to the nuclear medicine unit for ${ }^{131}$ I therapy, RSI were explained to the patient and accompanied household contact/s in details with answering all raised questions in a simple way. By the end of this visit, the participant and accompanied contact/s confirmed their understanding of all given instructions and ability to transfer RSI accurately to the rest of household contacts including adolescents and children's mothers. The purpose of using TLDs together with how and when to be applied was also clearly explained with the assurance of understanding all aspects concerned with TLDs. The participant and contact/s were given another printed copy of the instructions to be strictly followed. TLDs were dispensed in sufficient quantity for children and adolescents living in the same household. By the end of this visit, radioactive iodine therapy was given. Post- ${ }^{131}$ I therapy, the patient was sent back home in a separate private transportation other than that of accompanied household contact/s, with special precautions for reducing radiation exposure to the driver. On the fifth day post- ${ }^{131}$ I therapy, TLDs were collected. A questionnaire including information about the number of household children and adolescents, who was helping more and spending more time with the patient and their relation to the patient, socioeconomic status, and level of education were also collected. The readings of the collected TLDs were done in the Ministry of Health at Personal Radiation Dosage Program at Radiation Protection Department in Riyadh by using the TLD reader. All patients were assured of the complete confidentiality of all study data and that they will be informed about any detected radiation overexposure.

\section{Statistical analysis}

Statistical analysis was carried out on STATA version 13. Numeric variables were presented as the mean and standard deviation or the median and quartiles. Numeric variables were compared between two groups by the Student $t$ test if data were normally distributed and by the Mann-Whitney test if not. Data from more than two groups were compared by ANOVA if normally distributed and by Kruskal-Wallis test if not. Categorical variables were presented as percentages and were compared by chi-square test. For comparisons, a two-sided $p$ value was set at 0.05 .

\section{Results}

The current study included 39 patients treated with lowdose ${ }^{131} \mathrm{I}$ on an outpatient basis. Patients' criteria and given ${ }^{131}$ I dose are shown in Table 1 . Seventy-seven percent of patients were females and $59 \%$ of patients received ${ }^{131} \mathrm{I}$ for postoperative ablation post-total thyroidectomy for well-differentiated thyroid cancer. No statistically significant difference between education levels of thyrotoxic and cancer thyroid patients was detected. The given ${ }^{131}$ I dose for the latter group was significantly higher compared to the dose given to thyrotoxic patients.

The included 39 patients had 99 contacts sharing the same home in the post-therapy period aged $<18$ years, including 49 children up to 12 years of age. The criteria for those contacts are shown in Table 2. Among them, $70 \%$ were sons and daughters of patients. Only 13 adolescents (age 12-18 years) (26\%) and 17 mothers of 23 children (age < 12 years) (46.9\%) received direct RSI from RSO, while the remaining adolescents and mothers of young children got these RSI from the patient or from another family member. The mean CRE for the whole group was $284 \pm 178 \mathrm{uSv}$, with a range from 79 to $934 \mathrm{uSv}$ and 75th percentile of $334 \mathrm{uSv}$.

Age and gender of patients had no significant effects on CRE figures of the group of children and adolescents. Also, the patient education level had a non-significant effect on CRE to this group of contacts; yet, the lowest CRE were found in the five contacts of patients who got a post-graduate education with a mean value less than the mean CRE of all others (Tables 3 and 4).

Age, gender, and relation to the patient of household contacts were statistically insignificant in correlation with their CRE $(p>0.05)$. The sole factor that proved to 
Table 1 Characteristics and ${ }^{131}$ I dose of treated patients included in the study

\begin{tabular}{|c|c|c|c|c|}
\hline Characteristic & All patients $(n=39)$ & Thyrotoxic patients $(n=16)$ & Thyroid cancer patients $(n=23)$ & $p$ value \\
\hline \multicolumn{5}{|l|}{ Age, years } \\
\hline Mean \pm SD & $43.4 \pm 15.0$ & $38.3 \pm 13.7$ & $69.9 \pm 15.3$ & \multirow[t]{2}{*}{0.081} \\
\hline Range & $16.0-85.0$ & $16.0-61.0$ & $28.0-85.0$ & \\
\hline \multicolumn{5}{|l|}{ Gender, $n(\%)$} \\
\hline Male & $9(23.1)$ & $6(37.5)$ & $3(13.0)$ & \multirow[t]{2}{*}{0.075} \\
\hline Female & $30(76.9)$ & $10(62.5)$ & $20(87.0)$ & \\
\hline \multicolumn{5}{|c|}{ Patient's level of education, $n(\%)$} \\
\hline Illiterate & $10(25.6)$ & $2(12.5)$ & $8(34.8)$ & \\
\hline Primary & $5(12.8)$ & $3(18.8)$ & $2(8.7)$ & \\
\hline High school & $13(33.3)$ & $7(43.8)$ & $6(26.1)$ & \multirow[t]{3}{*}{0.267} \\
\hline University & $10(25.6)$ & $3(18.8)$ & $7(30.4)$ & \\
\hline Post-graduate & $1(2.6)$ & $1(6.3)$ & $0(0)$ & \\
\hline \multicolumn{4}{|l|}{ Given ${ }^{131}$ I dose, $\mathrm{MBq}(\mathrm{mCi})$} & \multirow[t]{3}{*}{$<0.01^{*}$} \\
\hline Range & $370-1110(10-30)$ & $370-740(10-20)$ & $1090-1110(29.7-30)$ & \\
\hline Mean, MBq & $795 \pm 329(21.5 \pm 8.9)$ & $527 \pm 134(14.2 \pm 3.7)$ & $1099 \pm 12(29.7 \pm 0.32)$ & \\
\hline
\end{tabular}

*Statistically significant

have a significant correlation with CRE was for adolescents and children of mothers who attended direct RSI sessions from RSO. Those who attended those sessions had significantly lower CRE compared to adolescents and children of mothers who got RSI from the patient or from another family member, with a mean value of $184 \pm 93 \mathrm{uSv}$ and $298 \pm 185 \mathrm{uSv}$, respectively $(p=0.038)$ (Table 5).

\section{Discussion}

Patients with thyroid disorders treated with ${ }^{131}$ I represent radiation hazard to household contacts including caregivers and family members. Many studies reported that no radiation overexposure was reported if RSI were applied strictly with radiation exposure figures within the radiation exposure constraints [20-22]. Few studies

Table 2 Characteristics and TLD readings of contacts of patients treated with ${ }^{131}$ |

\begin{tabular}{|c|c|c|c|c|}
\hline Characteristic & All family members $(n=99)$ & $\begin{array}{l}\text { Contacts of thyrotoxic } \\
(n=48)\end{array}$ & $\begin{array}{l}\text { Contacts of thyroid cancer } \\
(n=51)\end{array}$ & $\begin{array}{l}p \\
\text { value }\end{array}$ \\
\hline Age (years), mean $\pm S D$ & $11.9 \pm 4.7$ & $12.3 \pm 4.2$ & $11.4 \pm 5.1$ & 0.383 \\
\hline \multicolumn{5}{|l|}{ Gender, $n(\%)$} \\
\hline Male & $47(48.0)$ & 19 (39.6) & $28(55.8)$ & \\
\hline Female & $52(52.0)$ & $29(60.4)$ & $23(44.2)$ & 0.106 \\
\hline \multicolumn{5}{|l|}{ Contact relation to the patient, $n(\%)$} \\
\hline Son/daughter & $70(70.7)$ & $29(60.4)$ & $41(78.8)$ & 0.097 \\
\hline Sibling & $18(18.2)$ & $12(25.0)$ & $6(11.5)$ & \\
\hline Others & $11(11.1)$ & $7(14.6)$ & $4(7.7)$ & \\
\hline \multicolumn{5}{|l|}{ Direct education from RSO, $n(\%)$} \\
\hline - Adolescents (age 12-18) (13 adolescents) & 13 adolescents (26\%) & 7 adolescents (14.5) & 6 adolescents (11.8) & 0.882 \\
\hline $\begin{array}{l}\text { - Mothers of children ( } 17 \text { mothers for } 23 \text { children } \\
\leq 12 \text { years) }\end{array}$ & $\begin{array}{l}23 \text { children }(46.9 \% \text { of children }< \\
12 \text { years) }\end{array}$ & 10 children (20.4\%) & 13 children (26.5\%) & \\
\hline \multicolumn{5}{|l|}{ CRE (uSv) } \\
\hline Mean \pm SD & $284 \pm 178$ & $271 \pm 175$ & $296 \pm 181$ & \\
\hline Median & 215 & 208 & 234 & \\
\hline Q2-Q3 & $164-334$ & 160-339 & $166-391$ & 0.437 \\
\hline Range & 79-934 & $79-854$ & 107-934 & \\
\hline
\end{tabular}


Table 3 A comparison of CRE readings according to binary characteristics of patients

\begin{tabular}{|c|c|c|c|c|}
\hline & \multicolumn{3}{|c|}{ Values of CRE (uSv) } & \multirow{2}{*}{$\begin{array}{l}p \\
\text { value }\end{array}$} \\
\hline & Mean \pm SD & Median [quartiles] & 75th percentile & \\
\hline Contacts of patients $\leq 40$ years $(n=49)$ & $308 \pm 198$ & 222 & 391 & 0.783 \\
\hline Contacts of patients $>40$ years $(n=50)$ & $260 \pm 153$ & 209 & 292 & \\
\hline Contacts of male patients $(n=27)$ & $298 \pm 203$ & 231 & 317 & 0.831 \\
\hline Contacts of female patients $(n=72)$ & $279 \pm 167$ & 209 & 341 & \\
\hline
\end{tabular}

are there dealing with radiation exposure to children and adolescents sharing the same home with the patient in the post- ${ }^{131}$ I therapy period [23-26]. In the current study, we were concerned with external radiation exposure to this vulnerable group of children and adolescents. In our study, CRE to all children and adolescents were less than the $1 \mathrm{mSv}$ constraint, and $75 \%$ of them had CRE below $50 \%$ of this constraint. No statistically significant difference in CRE of children between contacts of patients treated with ${ }^{131}$ I for toxic goiter and those treated for cancer thyroid.

It was reported by Barrington et al. [25] that about $90 \%$ of children, contacts to patients treated with ${ }^{131}$ I were within the $1-\mathrm{mSv}$ dose limit. They concluded that hyperthyroid patients can be treated with ${ }^{131} \mathrm{I}$ on an outpatient basis, if they were given appropriate radiation protection instructions; yet, they raise the point that a special concern should be given to children aged less than 3 years, as 6/17 of them had exceeded CRE of 1 $\mathrm{mSv}$ limit. In our study, we had only 6 children less than 3 years with CRE figures ranged from 0.079 to 0.571 $\mathrm{mSv}$, with an overall $100 \%$ compliance for the constraint of $1 \mathrm{mSv}$.

On the other hand, Mathieu et al. [27] reported a median CRE of children who were household contacts of thyrotoxic patients treated with ${ }^{131} \mathrm{I}$ was $0.13 \mathrm{mSv}$ (18 outpatients received $200-600 \mathrm{MBq}$ ) with $88 \%$ received less than the constraint of $0.5 \mathrm{mSv}$ compared to $100 \%$ of thyroid cancer patients' relatives group (22 outpatients received $3700-7400 \mathrm{MBq}) .{ }^{131}$ I retention in the thyroid gland in thyrotoxic patients was accused for this difference, suggesting the need of more extended and stringent restriction periods according to the degree of residual thyroid activity. In our study, only 23 of the contacts exceeded the limit of $0.5 \mathrm{mSv}$ with CRE in the range from 0.5 to $0.934 \mathrm{mSv}$, which was still lower than the constraint of $1 \mathrm{mSv}$; out of these contacts, 11 were contacts of hyperthyroid patients. The compliance to $0.5 \mathrm{mSv}$ constraint in our study was $77 \%$ and $80.8 \%$ for contacts of hyperthyroid patients and thyroid cancer patients, respectively. In the current study, there are comparable values for this compliance together with insignificant difference in CRE figures between contacts of those with toxic goiter and those with welldifferentiated thyroid cancer despite the significantly higher doses of ${ }^{131}$ I given in the latter group. This is attributed to more ${ }^{131} \mathrm{I}$ retention in the intact thyroid gland in those with toxic goiter compared to little tracer retention by the small postoperative residual thyroid tissue in patients with thyroid cancer. This difference in tracer retention appears to compensate for the significant difference in the dose given and accused for the comparable exposure figures of contacts of both groups.

Few studies reported radiation overexposure to children who are household contacts of ${ }^{131}$ I-treated patients. Molyvda-Athanasopoulou et al. [26] reported an outpatient who got ${ }^{131}$ I therapy $(592 \mathrm{MBq})$ for her hyperthyroid state. They found that this patient had a 12year-old daughter who received $7.79 \mathrm{mSv}$ during the first 7 days post-therapy period. It was reported to be unexpected for a child in this age, who is able to understand and comply with given radiation safety precautions, to have such high radiation exposure figure. They suggested that in the presence of children in the house, it is better to leave the house for at least a week if possible, but if this cannot be done due to social reasons, giving ${ }^{131}$ I therapy with hospital admission should be considered [26]. Also, although Cappelen et al. [21] reported exposure figures below the $1-\mathrm{mSv}$ constraint, they reported an overexposure to a two-year-old child whose mother did not comply with the given radiation safety precautions. Besides, a recommendation was raised that

Table 4 A comparison of CRE readings according to patient's educational level

\begin{tabular}{llll}
\hline Educational level of patients (number of contacts) & Mean \pm SD & Median & 75th percentile \\
\hline Illiterate contacts (20) & $267 \pm 197$ & 208 & 294 \\
Primary school contacts (11) & $249 \pm 115$ & 205 & 298 \\
High school contacts (42) & $290 \pm 189$ & 226 & 354 \\
University education contacts (21) & $329 \pm 168$ & 286 & 387 \\
Post-graduate education contacts (5) & $237 \pm 13$ & 189 & 267 \\
\hline
\end{tabular}


Table 5 A comparison of CRE readings according to patient and contact characters

\begin{tabular}{|c|c|c|c|c|c|}
\hline \multirow[t]{2}{*}{ Characteristic } & \multirow[t]{2}{*}{ Categories $(n)$} & \multicolumn{3}{|c|}{ Values of CRE (uSv) } & \multirow[t]{2}{*}{$p$ value } \\
\hline & & Mean \pm SD & Median & 75th percentile & \\
\hline \multirow[t]{2}{*}{ Contact gender } & Male (47) & $311 \pm 191$ & 225 & 373 & \multirow[t]{2}{*}{0.225} \\
\hline & Female (52) & $259 \pm 163$ & 207 & 296 & \\
\hline \multirow[t]{2}{*}{ Direct education from RSO } & No (37 adolescents and 15 mothers of 26 children $\leq 12$ years) & $298 \pm 185$ & 233 & 391 & \multirow[t]{2}{*}{$0.038^{*}$} \\
\hline & Yes ( 13 adolescents and 17 mothers of 23 children $\leq 12$ years) & $184 \pm 93$ & 192 & 220 & \\
\hline \multirow[t]{3}{*}{ Contacts relation to the patient } & Son/daughter (70) & $305 \pm 79$ & 225 & 388 & \multirow[t]{3}{*}{0.196} \\
\hline & Sibling (18) & $201 \pm 103$ & 206 & 244 & \\
\hline & Others (11) & $287 \pm 137$ & 190 & 376 & \\
\hline
\end{tabular}

*Statistically significant

patients who share the same bedrooms or bathrooms with family members or mothers who are going to be treated with ${ }^{131} \mathrm{I}$ and has no one to look after her children in the post-therapy period should be treated on an inpatient basis by a study conducted on Omani patients [24]. All previous studies advised appropriate radiation protection precautions to be given with particular consideration to instructions for children $\leq 12$ years. The aforementioned studies support our recommendation of properly giving RSI by RSO to mothers in details. This should be done especially for the treated mothers, with special emphasis and more details about radiation safety precautions regarding their offsprings. Additionally, we have to be sure about their ability to comply with these instructions or at least confirming the presence of somebody else who can care for their child in the few days post-outpatient ${ }^{131}$ I therapy. Otherwise, if this is not feasible, we agree with other reports as regards the recommendation of giving low-dose ${ }^{131}$ I therapy on an inpatient basis to avoid radiation overexposure to children and adolescents.

Patients and contact factors such as age and gender together with patients' educational level as well as the relation of the contact to the patient had no statistically significant correlation with CRE ( $p$ values $>0.05)$. This goes with what was previously reported by Kuo et al. [28] stating that no factor (e.g., age, sex, renal function, and others) had a significant association with radiation exposure to household family members unless they were in close contact with the patient for a long time. Also, our results are in agreement with what was stated by Martin et al. [29] who confirmed the absence of a significant correlation between household contacts radiation exposure and patient education level.

It was found that adolescents and children of mothers who attended direct RSI sessions given by the RSO had significantly lower CRE figures. This emphasizes the value of getting RSI education directly from qualified professionals. The attendance of these education sessions by both patients and contacts is recommended, being associated with a significant reduction in CRE figures and more importantly ensuring the ability to comply with these instructions and to apply them strictly in the proper way. These recommendations are in agreement with other reports emphasizing the value of RSI and their proper application $[24,30]$.

\section{Conclusion}

Radiation exposure to all children and adolescents who are household contacts of outpatients treated with lowdose ${ }^{131} \mathrm{I}$ is below the radiation exposure constraint of 1 $\mathrm{mSv}$ with $75 \%$ of them having exposure figures below half of this constraint, raising the compliance to given RSI regarding this vulnerable group of household contacts to $100 \%$. We recommend attending direct RSI education sessions given from qualified professionals by both adolescents and mothers of children who share the same home with ${ }^{131}$ I-treated patients, representing the sole factor that has a significant correlation with lower radiation exposure level.

\section{Abbreviations \\ ${ }^{131}$ I: Radioactive iodine 131; ALARA: As low as reasonably achievable; CRE: Cumulative radiation exposure; RSI: Radiation safety instructions; RSO: Radiation safety officer; TLDs: Thermoluminescent dosimeters}

\section{Acknowledgements}

A lot of gratitude and acknowledgment are offered to King Abdulaziz City for Science and Technology (www.Kacst.edu.sa) of Saudi Arabia for its support during this study. This work was done through the fund supplied by the Strategic Technology Program-the National Plan for Science, Technology and Innovation (grant number \# AT-34-431).

\section{Authors' contributions}

KS was responsible for the idea of the study and writing of the manuscript. SW was responsible for the idea of the study, reviewing the patients' medical history, collection and analysis of the data, and writing of the manuscript. $A B$ was responsible for reviewing the patients' medical data, collection and analysis of the data, and writing of the manuscript. TAM was responsible for reviewing the patients' medical history, collection and analysis of the data, and writing of the manuscript. OT was responsible for the collection of the data and writing of the manuscript statistical analysis. MAM was responsible for the reading of TLDs, statistical analysis, and writing of the manuscript. MAE was responsible for giving radiation protection instructions and dispensing and collecting TLDs. AF was responsible for writing the manuscript and collection of the data. GH was responsible for giving radiation protection instructions, dispensing and collecting TLDs, and writing of the manuscript. All authors have read and approved the final manuscript. 


\section{Funding}

KACST Research Grant (Project No. AT-34-431(. They supplied the thermoluminescent dosimeters (TLDs) and covered the cost of their readings.

\section{Availability of data and materials}

The data that support the finding of this study are available from the statistical analysis unit in the Research Department in King Abdulla Medical City (KAMC), but restrictions apply to the availability of these data, which were used under license for the current study, and so are not publically available. Data are however available upon reasonable request and with permission of the Research Department in King Abdulla Medical City (KAMC).

\section{Ethics approval and consent to participate}

The study was submitted to and approved by the institutional ethics committee and IRB committee in King Abdulla Medical City (KAMC). The IRB number is 14-105. The institutional IRB is registered at the national Biomedical Ethics Committee, King Abdulaziz City for Science and Technology on 14-07-1433H, (Registration number, H-0-2-K-001).

A written informed consent was obtained from adolescents more than 16 years and from parents of contacts of patients less than 16 years.

\section{Consent for publication}

Consent for publication was signed by all patients. Also, we got consent from contacts included in the study, either from contacts more than 12 years themselves after verbal approval from their parents or from parents of contacts less than 12 years of age. This included an agreement for publication of their data regarding age, gender, household relatives, and radiation exposure figures, providing complete confidentiality regarding the name and address of included patients or contacts.

\section{Competing interests}

The authors declare that they have no competing interests.

\section{Author details}

${ }^{1}$ King Abdullah Medical City (KAMC), Makkah, Saudi Arabia. ${ }^{2}$ King Abdullah Medical City (KAMC), Jeddah Oncology Centre, Jeddah, Saudi Arabia. ${ }^{3}$ National Cancer Institute, Cairo, Egypt. ${ }^{4}$ Ministry of Health, Riyadh, Saudi Arabia.

Received: 21 October 2019 Accepted: 19 December 2019

Published online: 09 January 2020

\section{References}

1. de Klerk JMH. ${ }^{131}$ I therapy: inpatient or outpatient? Nucl Med. 2000;41(11): 1876-8.

2. Shinto SA, Kamaleshwaran KK, Shibu KD, Vyshak K, Antony J. Empiric therapy with low-dose I-131 in differentiated cancer thyroid: what is the magic number? World J Nucl Med. 2013;12(2):61-4.

3. NCRP Report No.155. Management of radionuclide therapy patients. Bethesda: National Council on Radiation Protection and Measurements (NCRP); 2006. https://ncrponline.org/shop/reports/report-no-155management-of-radionuclide-therapy-patients-2006/. Accessed 1 Nov 2018

4. Uslu-Besli L, Demir M, Yweyin N, Cavdar I. Radiation dose of caregivers could be reduced in thyroid carcinoma patients requiring high dose of radioactive iodine: a case report. Iran J Nucl Med. 2016;24:144-6.

5. Wakeford R. The cancer epidemiology of radiation. Oncogene. 2004;23: 6404-28.

6. Williams ED. Chernobyl and thyroid cancer. J Surg Oncol. 2006;94:670-7.

7. lonizing radiation, Part 1: X- and gamma-radiation, and neutrons. Lyon, International Agency for Research on Cancer, (IARC Monographs on the Evaluation of the Carcinogenic Risk to Humans, Volume 75, 2000. https:// www.ncbi.nlm.nih.gov/books/NBK401325/. Accessed 1 Nov 2018.

8. Moysich KB, Menezes RJ, Michalek AM. Chernobyl-related ionising radiation exposure and cancer risk: an epidemiological review. Lancet Oncol. 2002;3: 269-79.

9. Cardis E, Howe G, Ron E, Bebeshko V, Bogdanova T, Bouville A, et al. Cancer consequences of the Chernobyl accident: 20 years on. J Radiol Prot. 2006; 26:127-40.

10. Fushiki S. Radiation hazards in children - lessons from Chernobyl, Three Mile Island and Fukushima. Brain and Development. 2013;35:220-7.
11. Yamashita S, Suzuki S, Suzuki S, Shimura H, Saenko V. Lessons from Fukushima: latest findings of thyroid cancer after the Fukushima nuclear power plant accident. Thyroid. 2018;28:11-22.

12. Sorantin E, Weissensteiner S, Hasenburger G, Riccabona M. CT in children-dose protection and general considerations when planning a $C T$ in a child. Eur J Radiol. 2013;82:1043-9.

13. Nelson TR. Practical strategies to reduce pediatric CT radiation dose. J Am Coll Radiol. 2014;11:292-9.

14. Gelfand MJ, Lemen LC. PET/CT and SPECT/CT dosimetry in children: the challenge to the pediatric imager. Semin Nucl Med. 2007;37:391-8.

15. Gelfand MJ. Dose reduction in pediatric hybrid and planar imaging. Q J Nucl Med Mol Imaging. 2010;54:379-88.

16. Rivkees SA, Sklar C, Freemark M. Clinical review 99: the management of Graves' disease in children, with special emphasis on radioiodine treatment. J Clin Endocrinol Metab. 1998;83:3767-76.

17. Rivkees S. Radioactive iodine use in childhood Graves' disease: time to wake up and smell the I-131. J Clin Endocrinol Metab. 2004;89:4227-8.

18. Read CH Jr, Tansey MJ, Menda Y. A 36-year retrospective analysis of the efficacy and safety of radioactive iodine in treating young Graves' patients. J Clin Endocrinol Metab. 2004;89:4229-33.

19. Namwongprom S, Unachak K, Dejkhamron P, Ua-apisitwong S, Ekmahachai M. Radioactive iodine for thyrotoxicosis in childhood and adolescence: treatment and outcomes. J Clin Res Pediatr Endocrinol. 2013;5:95-7.

20. Grigsby PW, Siegel BA, Baker S, Eichling JO. Radiation exposure from outpatient radioactive iodine (1311) therapy for thyroid carcinoma. JAMA. 2000;283:2272-4.

21. Cappelen T, Unhjem JF, Amundsen AL, Kravdal G, Følling I. Radiation exposure to family members of patients with thyrotoxicosis treated with iodine-131. Eur J Nucl Med Mol Imaging. 2006;33:81-6.

22. Kocovska MZ, Vaskova O, Majstorov V, Kuzmanovska S, Gjorceva DP, Jokic VS. Effective dose to family members of patients treated with radioiodine131. J Phys Conf Ser. 2011;317:012012.

23. Jeong KH, Jung JW, Kim CB, Ahn BC, Lee HK, Yoo SJ, et al. Estimation of external radiation dose to caregivers of patients treated with radioiodine after thyroidectomy. Health Phys. 2014;106:466-74.

24. Al-Maskery I, Bererhi H. Radiation exposure levels in family members of omani patients with thyrotoxicosis treated with radioiodine (I) as outpatients. Sultan Qaboos Univ Med J. 2009;9:148-52.

25. Barrington SF, O'Doherty MJ, Kettle AG, Thomson WH, Mountford PJ, Burrell DN, et al. Radiation exposure of the families of outpatients treated with radioiodine (iodine-131) for hyperthyroidism. Eur J Nucl Med. 1999;26:686-92.

26. Molyvda-Athanasopoulou E, Karaveli M, Chatzigiannaki A, GotzamaniPsarrakou A. Unexpected dose to the daughter of a patient treated with iodine-131 for hyperthyroidism. Hell J Nucl Med. 2007;10:175-6.

27. Mathieu I, Caussin J, Smeesters P, Wambersie A, Beckers C. Recommended restrictions after 1311 therapy: measured doses in family members. Health Phys. 1999;76:129-36.

28. Kuo SF, Ho TY, Liou MJ, Lin KJ, Cheng RC, Chan SC, et al. Higher body weight and distant metastasis are associated with higher radiation exposure to the household environment from patients with thyroid cancer after radioactive iodine therapy. Medicine (Baltimore). 2017;96:e7942.

29. Martin R, Silva F, Colon MA, Roman D, Gonzalez TB. Evaluation of household radiation exposure and safety after ambulatory radioiodine ablation therapy. JTC. 2016;1:35-41.

30. Nantajit D, Saengsuda S, NaNakorn P, Saengsuda Y. High-dose radioiodine outpatient treatment: an initial experience in Thailand. Asia Ocean J Nucl Med Biol. 2015;3:66-71.

\section{Publisher's Note}

Springer Nature remains neutral with regard to jurisdictional claims in published maps and institutional affiliations. 